\title{
Increased Root Canal Endotoxin Levels are Associated with Chronic Apical Periodontitis, Increased Oxidative and Nitrosative Stress, Major Depression, Severity of Depression, and a Lowered Quality of Life
}

\author{
Cinthya Gomes ${ }^{1} \cdot$ Frederico Canato Martinho $^{2}$ - Décio Sabbatini Barbosa ${ }^{3}$. \\ Leonardo Santos Antunes ${ }^{1}$ • Helvécio Cardoso Corrêa Póvoa ${ }^{4}$. \\ Thiago Hissnauer Leal Baltus ${ }^{3}$ - Nayara Rampazzo Morelli ${ }^{3}$. \\ Heber Odebrecht Vargas ${ }^{5}$ - Sandra Odebrecht Vargas Nunes ${ }^{3}$. \\ George Anderson ${ }^{6}$ • Michael Maes ${ }^{3,7,8,9,10}$
}

Received: 21 January 2017 / Accepted: 7 April 2017 / Published online: 28 April 2017

(C) Springer Science+Business Media New York 2017

\begin{abstract}
Evidence indicates that major depression is accompanied by increased translocation of gut commensal Gramnegative bacteria (leaky gut) and consequent activation of oxidative and nitrosative (O\&NS) pathways. This present study examined the associations among chronic apical periodontitis (CAP), root canal endotoxin levels (lipopolysaccharides, LPS), O\&NS pathways, depressive symptoms, and quality of life. Measurements included advanced oxidation protein products (AOPP), nitric oxide metabolites (NOx), lipid peroxides (LOOH), - sulfhydryl (SH) groups, total radical trapping antioxidant parameter (TRAP), and paraoxonase (PON) 1 activity in participants with CAP, with and without depression, as well as healthy controls (no depression, no CAP). Root canal LPS levels were positively associated with CAP, clinical depression, severity of depression (as measured with the
\end{abstract}

Michael Maes

dr.michaelmaes@hotmail.com; http://scholar.google.co.th/

citations?user=1 wzMZ7UAAAAJ\&hl=th\&oi=ao

1 Department of Specific Formation, Institute of Health, School of Dentistry, UFF - Federal Fluminense University, Nova Friburgo, RJ, Brazil

2 Department of Restorative Dentistry, Endodontic Division, Institute of Science and Technology, UNESP - Univ Estadual Paulista, São José dos Campos, SP, Brazil

3 Graduation Program in Health Sciences, State University of Londrina (UEL), Paraná, Brazil
Hamilton Depression Rating Scale (HDRS) and the Beck Depression Inventory) and O\&NS biomarkers, especially NOx and TRAP. CAP-related depression was accompanied by increased levels of NOx, LOOH, AOPP, and TRAP. In CAP participants, there was a strong correlation $(r=0.734$, $p<0.001)$ between root canal LPS and the HDRS score. There were significant and positive associations between CAP or root canal endotoxin with the vegetative and physiosomatic symptoms of the HDRS as well as a significant inverse association between root canal endotoxin and quality of life with strong effects on psychological, environmental, and social domains. It is concluded that increased root canal LPS accompanying CAP may cause depression and a lowered quality of life, which may be partly explained by activated O\&NS pathways, especially NOx thereby enhancing
Department of Basic Science, Institute of Health, UFF - Universidade Federal Fluminense, Nova Friburgo, RJ, Brazil

5 Department of Psychiatry, Health Sciences Center, State University of Londrina, Londrina, Brazil

6 CRC, London and Scotland, Edinburgh, UK

7 Department of Psychiatry, Faculty of Medicine, Chulalongkorn University, Bangkok, Thailand

8 Department of Psychiatry, Medical University Plovdiv, Plovdiv, Bulgaria

9 Revitalis, Waalre, the Netherlands

10 IMPACT Strategic Research Center, Barwon Health, Deakin University, Geelong, VIC, Australia 
hypernitrosylation and thus neuroprogressive processes. Dental health and "leaky teeth" may be intimately linked to the etiology and course of depression, while significantly impacting quality of life.

Keywords Depression · LPS · Endotoxin · Inflammation . Oxidative and nitrosative stress $\cdot$ Antioxidants $\cdot$ Chronic apical periodontitis

\section{Introduction}

Research on the pathophysiology of clinical depression has highlighted activated immune-inflammatory, oxidative and nitrosative stress (O\&NS) pathways [1,2]. Immune activation and chronic mild inflammation in depression are indicated by increased plasma levels of positive acute phase proteins, e.g., haptoglobin and C-reactive protein (CRP), and increased levels of T helper cells (Th1) and M1 macrophagic cytokines $[1,3,4]$. Lowered levels of endogenous antioxidants and antioxidant enzymes, including high-density lipoprotein (HDL) cholesterol, vitamin E, paraoxonase (PON)1, coenzyme Q10, and zinc, are often observed in clinical depression and animal models of depression [2, 5-10]. Immune activation and chronic inflammatory processes are accompanied by increased production of reactive oxygen species (ROS) and reactive nitrogen species (RNS), such as superoxide, peroxides, nitric oxide (NO), and peroxynitrites [10-12]. When the pro-oxidant/antioxidant ratio increases, damage by O\&NS processes may cause lipid peroxidation, oxidative damage to membrane lipids and anchorage molecules, protein oxidation and hypernitrosylation, i.e., binding of NO (nitroso-) to proteins $[11,12]$. Increased levels of peroxides, malondialdehyde (indicating lipid peroxidation), advanced oxidation protein products (AOPP), indicating protein oxidation, NO production, and NO-binding to proteins are all evident in clinical depression $[2,7,10,12-14]$.

Alterations in the gut-brain-axis following increased gut permeability (leaky gut) may contribute to activated immune-inflammatory and O\&NS pathways and subsequently to depression symptoms $[15,16]$. One mechanism explaining this pathway is translocation of Gram-negative bacteria causing increased endotoxin or lipopolysaccharide (LPS) levels in blood, which subsequently may activate Toll-like receptors (TLR) 2/4 leading to increased production of Th1 and M1 macrophagic cytokines as well as ROS/RNS $[17,18]$. Clinical depression is accompanied by increased serum levels of immunoglobulin (Ig)A and IgM directed against LPS and antigens of different Gram-negative gut, commensal bacteria, including Hafnia alvei, Pseudomonas aeruginosa, Morganella morganii, Proteus mirabilis, Pseudomonas putida, Citrobacter koseri, and Klebsiella pneumoniae [19, 20]. Indicants of bacterial translocation in clinical depression are also associated with signs of inflammation and O\&NS, including lipid peroxidation and hypernitrosylation [16].

Bacterial translocation of Gram-negative bacteria may also be induced through periodontal disease, including chronic apical periodontitis (CAP) [21, 22], which is a chronic inflammatory disorder of the periradicular tissues caused by bacterial invasion of the apex of the tooth root [23]. CAP not only causes local tissue inflammatory destruction, but also systemic inflammatory responses, which may ultimately predispose toward systemic disease, including cardiovascular disorder [22, 24-26]. There is a significant association between periodontitis and depression [27]. In a nationwide populationbased study periodontitis was a significant risk factor for depression with an adjusted hazard ratio of 1.73 [28]. Moreover, lowered self-esteem and higher levels of stress have been reported in subjects with periodontal disease [29-31]. Gramnegative and -positive bacteria, including Porphyromonas gingivalis, Prevotella intermedia, Fusobacterium nucleatum, Pseudomonas aeruginosa, Bacteroides forsythus, Campylobacter rectus, Peptostreptococcus micros, Staphylococcus intermedius, and Treponema sp. play an important role in the pathophysiology of periodontitis and CAP [22, 32, 33]. There are, however, no data whether LPS levels in the root canals of patients with CAP are associated with depression and systemic O\&NS processes.

The aims of this study were to delineate whether root canal endotoxin in patients with CAP is increased in patients with depression as compared to those without depression and controls; whether there are significant associations between root canal endotoxin contents and severity of illness, quality of life and O\&NS, including hydroperoxide, AOPP, NO production, and antioxidant defenses. The a priori hypotheses are that increased root canal endotoxin levels are associated with depression, severity of depression, a lowered quality of life, increased O\&NS, and lowered antioxidant defenses.

\section{Participants and Methods}

\section{Participants}

We recruited subjects with CAP with and without depression, diagnosed according to DSM-IV-TR, who attended the Dental Clinic of the School of Dentistry at the Fluminense Federal University, Nova Friburgo, RJ, Brazil. Healthy volunteers were sampled from the same catchment area. To be included, participants had to be over 18 years of age or older and be able to read and write Portuguese language. CAP participants were only included if they planned to have their teeth extracted at this dental clinic. CAP patients with depression were excluded when a current or lifetime axis-I diagnoses, other than major depression, was present including autism, schizophrenia, cognitive disorders, and substance abuse. CAP patients without 
depression and healthy controls (no CAP, no depression) were excluded if a lifetime or current diagnosis of axis-I diagnosis was evident, including major depression, dysthymia, bipolar disorder, autism, schizophrenia, cognitive disorders, and substance abuse. Both CAP and healthy subjects were excluded if any major medical disorder was present, including immune and autoimmune disorders, diabetes, lupus erythematosus, colitis ulcerosa, and Chrohn's disease.

Based on the inclusion criteria, we recruited 59 subjects. Due to the abovementioned exclusion criteria, we excluded some subjects with CAP and depression, namely one with autism, one with schizophrenia, three with cognitive disorders, and two with substance abuse. We also excluded controls without depression and CAP, namely two with a current diagnosis of diabetes, two with immune disorders, and one with substance abuse. As a consequence, the final study sample comprised 23 normal controls and 24 subjects with depression. The study was approved by the Ethics Committee of the Federal Fluminense University, Nova Friburgo, RJ, Brazil (No. 1.555.226). Written informed consent was obtained from all participants.

\section{Measurements}

All participants were assessed by a senior psychiatrist and senior dentist using semi-structured interviews. Intraoral clinical and radiographic exams were conducted in order to identify the presence of extensive tooth cavities in demand of extraction and presence of CAP, respectively. All participants completed a questionnaire consisting of sociodemographic data, smoking history, and data on family history of psychiatric disease. The psychiatric interview consisted of (a) structured clinical interview, clinical version (SCID-I) to make the diagnosis of current/lifetime axis-I disorders according to DSM-IV-TR criteria. (b) 17-item Hamilton Depression Rating Scale (HDRS) in a validated Portuguese translation [34]. We also examined three different subscores, namely sum of items $1-3,7$, and 17 reflecting "core depressive" symptoms (HDRSd); sum of items 4-6, 8, and 16 reflecting "vegetative symptoms" (HDRSv), and sum of items 11-15, reflecting "physio-somatic symptoms" (HDRSps). (c) Beck Depression Inventory (BDI) in a validated Portuguese translation adapted to the Brazilian population [35]. (d) Quality of life was measured using the WHO Quality of Life (WHOQoL)-BREF in a validated Portuguese translation [36]. We computed the raw scores on the four WHOQolBREF domains (namely (1) physical health, (2) psychological health, (3) social relationships, and (4) environment) rather than the transformed scores (which convert the lowest and highest scores to 0 and 100 , respectively). Total healthrelated Qol was estimated by summing of the raw scores of the four domains. (e) We employed the Alcohol, Smoking, and Substance Involvement Screening Test (ASSIST) to screen for the use of hypnotics and alcohol, translated and adapted to Portuguese by Henrique et al. [37]. In order to assess severity of tobacco dependence, we used the Fagerstrom Test for Nicotine Dependence in a Portuguese translation [38]. Number of pack years was calculated as the number of cigarettes smoked per day multiplied by number of years smoked and divided by 20 (one pack has 20 cigarettes). As a surrogate but adequate measurement of body mass index we measured waist circumference.

\section{Plasma O\&NS Biomarkers}

After an overnight fast we collected blood at 8:00 a.m., the same day as teeth extractions, for the assay of O\&NS and antioxidant biomarkers, including AOPP, hydroperoxides $(\mathrm{LOOH})$, nitric oxide (NO) metabolites (NOx), sulfhydryl $(-\mathrm{SH})$ groups, PON1 total activity, and total radical trapping antioxidant parameter (TRAP). To measure protein oxidation, AOPP in plasma was quantified - using the method described by Hanasand et al. [39] in a microplate reader, PerkinElmer $囚$, model EnSpire (Waltham, MA, EUA) at a wavelength of $340 \mathrm{~nm}$. AOPP concentration was expressed in micromoles of equivalent chloramine T. LOOH were determined according to an adaptation of the technique described by GonzalesFlecha et al. [40] and Panis et al. [41]. This method uses the compound tert-butyl hydroperoxide to start a lipid chain reaction that can be detected by photon emission during the formation of lipid hydroperoxides. Readings were performed in a Glomax luminometer (TD 20/20 Turner Designers, E.U.A.) over $1 \mathrm{~h}$ at $1 \mathrm{reading} / \mathrm{s}$. Results were expressed as relative units of light. NO levels were assessed indirectly by determining the plasma nitrite concentration using an adaptation of the technique described Navarro-Gonzálvez et al. [42]. This method is based on the reduction of the nitrate present in the sample to nitrite by oxidation-reduction reactions mediated by the system cadmium-copper reagent. Thereafter, Griess reagent was added to induce diazotization, forming a colored complex and subsequent detection at $540 \mathrm{~nm}$. The quantification of NOx was made in a microplate reader Asys Expert Plus, Biochrom ${ }^{\circledR}$ (Holliston, MA, USA). The nitric oxide metabolites concentrations were expressed in micromoles. Sulfhydryl groups from proteins were evaluated by the method described by $\mathrm{Hu}$ [43], which is based on the reaction of 5,5-dithiobis-2 nitrobenzoic acid (DTNB) with sulfhydryl groups. Determination was conducted in a spectrophotometer Helios $\alpha$, Thermo Spectronic ${ }^{\circledR}$ (Waltham, MA, USA) at $412 \mathrm{~nm}$. Results are expressed as micromoles per milligram of plasmatic protein. Total plasmatic activity of PON1 was determined by the method described by Richter et al. [44]. The rate of hydrolysis of phenyl acetate was determined in a microplate reader EnSpire, PerkinElmer ${ }^{\circledR}$ (Waltham, MA, USA) at $270 \mathrm{~nm}$ and the temperature maintained at $25^{\circ} \mathrm{C}$. Measures were recorded every $4 \mathrm{~min}$, each of $15 \mathrm{~s}$. The activity was 
expressed in units per milliliter based on the phenyl acetate molar extinction coefficient of $1.31 \mathrm{mMol} / \mathrm{L} \mathrm{cm}^{-1}$. TRAP was evaluated according to the method described by Repetto et al. [45] in microplate reader Victor X-3, PerkinElmer ${ }^{\circledR}$ (Waltham, MA, USA). Experimental conditions were running time of $25 \mathrm{~min}$, response range from 300 to $620 \mathrm{~nm}$ and a temperature of $30{ }^{\circ} \mathrm{C}$. This method detects hydro- and/or lipo-soluble antioxidants in serum. The results were expressed in micromoles trolox. All analytes were assayed in one and the same run by the same technician, who was blinded to the source of the clinical data. The intra-assay $\mathrm{CV}$ values were all $<6 \%$.

\section{Procedures}

Identified teeth were extracted according to a standard surgical protocol. Briefly, following mouth wash with antiseptic solution (Listerine - Johnson \& Johnson do Brasil Indústria e Comércio de Produtos para Saúde Ltda, SP, Brazil) extra oral asepsis was carried out with iodine alcohol (Povidine Johnson \& Johnson do Brasil Indústria e Comércio de Produtos para Saúde Ltda, SP, Brazil). Anesthesia was performed using articaine hydrochloride and epinephrine 1:100.000 (DFL Indústria e Comércio S.A, RJ, Brazil). Subsequently, syndesmotomy was performed using Sindestome (Duflex, S.S.White, RJ, Brazil) and the tooth was extracted using forceps (Duflex, S.S.White, RJ, Brazil). Curettage of the peri-apical lesion and alveolus was performed with surgical curettes. Hemostasis was performed with gauze followed by suture with needle holder (Duflex, S.S.White, RJ, Brazil) and suture needle line 4-0 needle CT $1 / 21.7 \mathrm{~cm}$ (Duflex, S.S.White, RJ, Brazil). The extraction of the pulp was performed according to standardized methods as previously described by us $[46,47]$. In short: the sampling of the infection pool, which includes bacteria, endotoxins and remnants of pulp tissue, is performed by placement of a sterile paper point inside the root canal for $1 \mathrm{~min}$. Consequently, the paper point is placed in a $1.5-\mathrm{mL}$ plastic tube (sterile and free of endotoxins) and the sampling specimen is reconstituted with $1 \mathrm{~mL}$ of limulus amebocyte lysate (LAL) water (LAL Reagent Water), whereby the extraction of the infection pool from the paper point is mechanically performed by agitation and sonication from the samples in a vortex for $60 \mathrm{~s}$. The root canal sample specimens are then frozen at $-80{ }^{\circ} \mathrm{C}$ until assayed for endotoxin.

\section{Endotoxin Assay}

A turbidimetric test (Kit KQCL, BioWhitaker, Inc., Walkersville, MD) and the limulus amebocyte lysate (LAL) technique were used to measure endotoxin levels. The test procedure was performed following the manufacturer's instructions. For the calculation of the amount of endotoxins in root canal samples, a standard curve was plotted by using endotoxins supplied in the kit. The analyses were carried out in triplicate for each dilution in the concentration range as provided by the manufacturer. These results were used to produce a linear regression curve for the determination of linear and angular parameters. Additionally, the correlation coefficient and replicates relative standard deviation were determined. A 96-well microplate (Corning Costar, Cambridge, MA) was placed on a heating block at $37^{\circ} \mathrm{C}$ and maintained at this temperature throughout the assay. Next, the endotoxin samples were suspended in 1-mL LAL water, supplied with the kit, and agitated in a vortex for $60 \mathrm{~s}$, thereafter being serially diluted to a concentration of $10^{-1}$. Immediately afterwards, $100 \mu \mathrm{L}$ of the blank, followed by the standard endotoxin solutions at different concentrations and $100 \mu \mathrm{L}$ of the samples were added in duplicate in the 96-well microplate. Endotoxin absorbance was measured using an enzymelinked immunosorbent assay plate reader (Ultramark; BioRad Laboratories, Hercules, CA) at $340 \mathrm{~nm}$. The mean absorbance value of the standard solutions was directly proportional to the concentration of endotoxins and the concentration was determined from the standard curve. The intraassay CV values were $<10 \%$. Previously, we compared different tests using the LAL principle for the analysis of endotoxins in root canal contents and we concluded that quantitative kinetic-turbidimetric (used here) and kinetic-chromogenic LAL methods are best fitted for the analysis of endotoxins in root canal infection, both being more precise and allowing better reproducibility compared with the endpoint-QCL assay [48].

\section{Statistical Analysis}

We used analyses of variance (ANOVAs) to check differences in scale variables among study groups and analyses of contingency tables, the $X^{2}$ test, to assess associations between nominal variables. Pearson's product moment, Spearman's rank order, and point-biserial correlation analyses were employed to assess correlations between two sets of variables. We employed multivariate general linear model (GLM) analyses to delineate the multivariate effects of selected explanatory variables on dependent variables. Thus, we used root canal LPS and/or the O\&NS biomarkers as dependent variables and the clinical diagnosis of depression as explanatory variables, while adjusting for relevant background variables including age, sex, and smoking. We also used severity of depression or the WHOQoL-BREF data as dependent variables and the clinical diagnosis of periodontitis or root canal LPS levels as explanatory levels while adjusting for the relevant background variables. Consequently, tests for betweensubjects effects were employed to delineate the univariate effects of significant predictor variables on each of the dependent variables. Stepwise automatic regression analysis or univariate GLM analyses were used to assesses the effects of 
selected explanatory variables on one dependent variable. We used Ln or square root transformations to normalize the data distribution (tested with the Kolmogorov-Smirnov test) of biomarkers where needed, namely LPS, AOPP, NOx, and LOOH. To provide an integrative O\&NS index, a $z$ unit weighted composite score was computed, and consequently raw values of AOPP, $\mathrm{LOOH}$, and NOx were converted into $z$ scores and added up as zO\&NS $=\mathrm{zAOPP}+\mathrm{zLOOH}+\mathrm{zNOx}$. All results of regression analyses were checked for collinearity using collinearity statistics, VIF, and tolerance. All statistical analyses were performed using IBM SPSS windows version 22. Tests were two-tailed and a $p$ value of 0.05 was used for statistical significance.

\section{Results}

Table 1 shows the sociodemographic, clinical, and biomarker data of all participants divided into those with increased root canal LPS (as determined with the median-split method) versus those with lower LPS values. No $p$ corrections were employed to interpret the results presented in Table 1 as these univariate tests together with the correlation matrices between the variables were used to delineate the explanatory and background variables, which were employed in the ultimate multivariate GLM analyses as independent determinants of the dependent variables. Nevertheless, Table 1 shows that there were no significant differences in age, sex distribution, waist circumference, hypertension, and smoking between the study groups. Only two subjects smoked between 11 and 20 cigarettes/day, while the others $(n=9)$ smoked 10 or less cigarettes/day. Participants with higher root canal LPS levels showed increased prevalence of CAP and depression and increased HDRS (and subscores) and BDI values and lowered WHOQoL-BREF (and domain) values. In the same participants, there was a trend toward increased AOPP values and increased LOOH, NOx, zO\&NS, and TRAP values. There were no differences in $-\mathrm{SH}$ groups and PON1 values. In the total study group, there were significant correlations between root canal LPS and HDRS $(r=0.799, p<0.001, n=47)$; BDI $(r=0.759, p<0.001, n=47)$; and WHOQoL-BREF score $(r=-0.529, p<0.001, n=46)$. In subjects with CAP, there were significant correlations between root canal LPS and HDRS $(r=0.734, p<0.001, n=34)$ and the BDI $(r=0.704, p<0.001, n=34)$.

Table 2 displays the results of a multivariate GLM analyses with LPS and the six O\&NS biomarkers as dependent variables and clinical depression as primary explanatory variable while adjusting for age, sex, and smoking. All four explanatory variables had significant effects on the biomarkers. Tests for between-subject effects and the estimated marginal mean values show that clinical depression was significantly associated with increased root canal LPS, plasma AOPP, NOx,
LOOH, and TRAP values, while there were no significant effects of -SH groups and PON1 activity. There were sexrelated differences in AOPP, PON1, and TRAP, while age had a significant effect on LPS and LOOH (positive) and SH groups (negative). Smoking had a small, although significant, effect on LOOH and NOx (positive). Univariate GLM analysis showed significant effects $(F=7.49, \mathrm{df}=5 / 39$, $p<0.001)$ of clinical depression $(F=12.97, \mathrm{df}=1 / 39$, $p=0.001)$; age $(F=6.05, \mathrm{df}=1 / 39, p=0.018)$; and smoking $(F=9.72, \mathrm{df}=1 / 39, p=0.003)$, but not $\mathrm{CAP}(F=2.18, \mathrm{df}=1 /$ $39, p=0.148)$ and $\operatorname{sex}(F=3.18, \mathrm{df}=1 / 39, p=0.082)$ on zO\&NS. This O\&NS index was significantly higher in participants with depression (mean $\pm \mathrm{SD}=1.98 \pm 0.58$ in $z$ values) than in subjects without depression $(-0.45 \pm 0.39$ in $z$ values $)$.

We have examined other putative explanatory variables in this multivariate GLM analysis but none were significant, including waist circumference $(F=0.72, \mathrm{df}=7 / 30, p=0.659)$; hypertension $(F=1.30, \mathrm{df}=7 / 32, p=0.280)$; ASSIST alcohol $(F=1.68, \mathrm{df}=7 / 32, p=0.149) ;$ ASSIST hypnotics $(F=1.64$, $\mathrm{df}=7 / 32, p=0.161) ;$ Fagerstrom total score $(F=1.72, \mathrm{df}=7 /$ $33, p=0.138)$; and cigarette month-packs/year $(F=0.70$, $\mathrm{df}=7 / 33, p=0.600$ ).

Table 3 shows the results of two different multivariate GLM analyses with the O\&NS biomarkers as dependent variables and CAP or root canal LPS levels as explanatory variables, while adjusting for background variables. We found that CAP did not have significant effects on the O\&NS biomarkers, while root canal LPS was a significant predictor variable. Tests for between-subject effects showed that root canal LPS was associated with increased NOx, TRAP, and AOPP, after adjusting for sex, age, and smoking. Univariate GLM analysis showed that root canal LPS was also associated with an increased zO\&NS index $(F=28.90$, $\mathrm{df}=1 / 40, p=0.004)$. We have also examined the combined effects of depression and CAP on the six O\&NS biomarkers. Multivariate GLM analysis showed that depression $(F=6.52$, df $=6 / 32, p<0.001)$ (and age, sex, and smoking), but not CAP $(F=1.99, \mathrm{df}=6 / 32, p=0.096)$, had a significant effect on the six O\&NS biomarkers. We have also examined the effects of CAP and depression on LPS. Univariate GLM analysis showed that $92.6 \%$ of the variance in LPS levels $(F=287.46, \mathrm{df}=2 / 44, p<0.001)$ was explained by CAP $(F=76.49, \mathrm{df}=1 / 44, p<0.001)$ and depression $(F=138.85$, df $=1 / 44, p<0.001)$. Root canal LPS was significantly higher in depressed subjects $(206.3 \pm 14.4 \mathrm{EU} / \mathrm{mL})$ than in those without depression $(25.0 \pm 10.3 \mathrm{EU} / \mathrm{mL})$ and higher in those with CAP $(141.2 \pm 14.4 \mathrm{EU} / \mathrm{mL})$ than in those without $(90.5 \pm 16.4 \mathrm{EU} / \mathrm{mL})$.

Table 4 shows the results of three multivariate GLM analyses with the WHOQol-BREF, HDRS, and BDI as dependent variables and CAP or LPS as explanatory variables. Age, sex, smoking, and waist circumference were not significant in this 
Table 1 Sociodemographic, clinical, and biomarker data in subjects with increased root canal endotoxin levels versus those with lower root canal endotoxin levels

\begin{tabular}{|c|c|c|c|c|c|}
\hline Variables & LPS $<119.4 \mathrm{EU} / \mathrm{mL}$ & $\mathrm{LPS} \geq 119.4 \mathrm{EU} / \mathrm{mL}$ & $F / X^{2}$ & $\mathrm{df}$ & $p$ value \\
\hline Age (years) & $41.4(20.6)$ & $45.9(13.1)$ & 0.80 & $1 / 45$ & 0.375 \\
\hline $\operatorname{Sex}(+/ ふ)$ & $13 / 10$ & $15 / 9$ & 0.17 & 1 & 0.676 \\
\hline Chronic apical peridontitis (no/yes) & $13 / 10$ & $0 / 24$ & FEPT & - & $<0.001$ \\
\hline Major depression (no/yes) & $22 / 1$ & $1 / 23$ & FEPT & - & $<0.001$ \\
\hline Waist circumference $(\mathrm{cm})$ & $89.5(16.6)$ & $91.3(11.9)$ & 0.18 & $1 / 43$ & 0.677 \\
\hline Education (years) & $9.9(4.1)$ & $6.6(3.9)$ & 6.66 & $1 / 38$ & 0.014 \\
\hline Hypertension (no/yes) & $18 / 5$ & $13 / 11$ & 3.04 & 1 & 0.081 \\
\hline Smoking (no/yes) & $19 / 4$ & $15 / 9$ & 2.37 & 1 & 0.123 \\
\hline HDRS & $3.1(1.8)$ & $14.0(5.6)$ & 78.78 & $1 / 45$ & $<0.001$ \\
\hline BDI & $2.9(6.3)$ & $17.5(10.6)$ & 32.60 & $1 / 45$ & $<0.001$ \\
\hline HDRSd & $2.3(0.8)$ & $4.5(2.5)$ & 15.37 & $1 / 45$ & $<0.001$ \\
\hline HDRSv & $0.3(1.1)$ & $4.6(2.5)$ & 58.05 & $1 / 45$ & $<0.001$ \\
\hline HDRSps & $0.04(0.2)$ & $2.4(1.9)$ & 33.18 & $1 / 45$ & $<0.001$ \\
\hline Total WHOQol-BREF & $94.9(10.8)$ & $78.0(14.7)$ & 19.37 & $1 / 44$ & $<0.001$ \\
\hline WHO-Physical & $29.3(4.7)$ & $23.7(5.4)$ & 14.80 & $1 / 45$ & $<0.001$ \\
\hline WHO-Psychological & $25.6(2.4)$ & $20.4(5.6)$ & 17.17 & $1 / 45$ & $<0.001$ \\
\hline WHO-Social relationships & $12.0(1.8)$ & $10.2(2.3)$ & 9.57 & $1 / 44$ & 0.003 \\
\hline WHO-Environmental & $28.0(4.2)$ & $23.8(5.0)$ & 9.53 & $1 / 45$ & 0.003 \\
\hline Endotoxin $(\mathrm{EU} / \mathrm{mL})^{\mathrm{a}}$ & $21.5(31.1)$ & $232.2(63.8)$ & 51.34 & $1 / 45$ & $<0.001$ \\
\hline $\operatorname{AOPP}(: M)^{a}$ & $89.4(37.0)$ & $169.5(220.1)$ & 3.05 & $1 / 44$ & 0.088 \\
\hline LOOH (RLU 10E6) ${ }^{a}$ & $860(87)$ & $967(166)$ & 6.49 & $1 / 43$ & 0.015 \\
\hline $\mathrm{NOx}(: \mathrm{M})^{\mathrm{a}}$ & $7.8(3.8)$ & $10.5(5.1)$ & 5.31 & $1 / 44$ & 0.026 \\
\hline$-\mathrm{SH}$ groups $(: \mathrm{M})$ & $378.4(53.2)$ & $385.6(52.0)$ & 0.22 & $1 / 44$ & 0.643 \\
\hline TRAP (:M Trolox) & $759.4(131.6)$ & $928.4(158.6)$ & 15.30 & $1 / 43$ & $<0.001$ \\
\hline PON1 (U/mL) & $161.7(44.6)$ & $176.1(39.3)$ & 1.33 & $1 / 43$ & 0.256 \\
\hline $\mathrm{ZLOOH}+\mathrm{AOPP}+\mathrm{NOX}$ & $-0.98(1.48)$ & $0.93(2.46)$ & 9.79 & $0 / 43$ & $<0.001$ \\
\hline
\end{tabular}

All results are shown as mean (SD). All results of analyses of variance (ANOVA), or analyses of contingency tables $\left(X^{2}\right)$ or FEPT: Fisher's exact probability test. All results of analyses of variance (ANOVA), or analyses of contingency tables $\left(X^{2}\right)$ or FEPT

${ }^{\text {a }}$ Processed in Ln or square root transformation

HDRS Hamilton Depression Rating Scale; BDI Beck Depression Inventory; WHOQoL-BREF WHO Quality of Life-BREF; HDRSd HDRS subscore "core depressive symptoms," that is sum of items 1, 2, 3, 7, and 17; HDRSv HDRS subscore "vegetative symptoms," that is sum of items 4, 5, 6, 8, and 16; HDRSps HDRS subscore "physio-somatic symptoms," that is sum of items 11,12,13,14, and 15; AOPP advanced oxidation protein products; LOOH hydroperoxide; NOx nitric oxide metabolites; - SH groups - sulfhydryl groups; TRAP total radical trapping antioxidant parameter; PON1 paraoxonase total activity

regression but hypertension was. Therefore, we have entered hypertension as an additional explanatory variable. There were significant effects of CAP together with hypertension on the clinical rating scale scores. Tests for between-subject effects and estimated marginal mean values showed that CAP was significantly and positively associated with HDRS and BDI and inversely with WHOQoL-BREF. Hypertension was significantly and positively associated with HDRS score (see also estimated marginal mean values). Regression \#2, Table 4 shows that there was a significant effect of root canal LPS on the clinical rating scale scores (hypertension was not significant in this regression). Tests for between-subject effects showed that root canal LPS was significantly and positively associated with HDRS and BDI and negatively with WHOQoL-BREF. Regression \#3, Table 4 shows that NOx (but not other O\&NS biomarkers) had a significant effect on the three rating scales and that increased NOx was associated with raised BDI and HDRS values.

Table 5 shows the results of three multivariate GLM analyses with the three HDRS subscales as dependent variables and CAP or root canal LPS as explanatory variables. CAP and especially increased root canal LPS were strongly associated with the HDRS subscores, while tests for between-subject effects showed significant effects of root canal LPS on all three subscales, especially the vegetative and physio-somatic subscales. Multivariate GLM analysis \#3 showed that NOx 
Table 2 Results of multivariate GLM analyses with root canal endotoxin levels and oxidative and nitrosative stress and antioxidant biomarkers as dependent variables

\begin{tabular}{|c|c|c|c|c|c|c|}
\hline Tests & Dependent variables & Explanatory variables & $F$ & df & $p$ value & Partial eta squared \\
\hline \multirow[t]{4}{*}{ Multivariate } & \multirow[t]{4}{*}{ All 7 biomarkers } & Depression & 19.40 & $7 / 32$ & $<0.001$ & 0.809 \\
\hline & & Sex & 4.78 & $7 / 32$ & 0.001 & 0.511 \\
\hline & & Age & 10.62 & $7 / 32$ & $<0.001$ & 0.699 \\
\hline & & Smoking & 2.93 & $7 / 32$ & 0.017 & 0.391 \\
\hline \multirow[t]{7}{*}{ Between-subject effects } & Endotoxin & $\begin{array}{l}\text { Depression }(+) \\
\text { Age }(+)\end{array}$ & $\begin{array}{l}57.82 \\
18.31\end{array}$ & $\begin{array}{l}1 / 38 \\
1 / 38\end{array}$ & $\begin{array}{l}<0.001 \\
<0.001\end{array}$ & $\begin{array}{l}0.603 \\
0.325\end{array}$ \\
\hline & AOPP & $\begin{array}{l}\text { Depression }(+) \\
\text { Sex }(M>F)\end{array}$ & $\begin{array}{l}4.08 \\
8.88\end{array}$ & $\begin{array}{l}1 / 38 \\
1 / 38\end{array}$ & $\begin{array}{l}0.050 \\
0.005\end{array}$ & $\begin{array}{l}0.097 \\
0.189\end{array}$ \\
\hline & SH groups & Age (-) & 26.16 & $1 / 38$ & $<0.001$ & 0.408 \\
\hline & $\mathrm{LOOH}$ & $\begin{array}{l}\text { Depression (+) } \\
\text { Smoking }(+) \\
\text { Age }(+)\end{array}$ & $\begin{array}{l}4.55 \\
4.43 \\
8.34\end{array}$ & $\begin{array}{l}1 / 38 \\
1 / 38 \\
1 / 38\end{array}$ & $\begin{array}{l}0.039 \\
0.042 \\
0.006\end{array}$ & $\begin{array}{l}0.107 \\
0.104 \\
0.180\end{array}$ \\
\hline & PON1 & $\operatorname{Sex}(F>M)$ & 4.43 & $1 / 38$ & 0.042 & 0.104 \\
\hline & NOX & $\begin{array}{l}\text { Depression (+) } \\
\text { Smoking (+) }\end{array}$ & $\begin{array}{l}6.16 \\
5.05\end{array}$ & $\begin{array}{l}1 / 38 \\
1 / 38\end{array}$ & $\begin{array}{l}0.018 \\
0.031\end{array}$ & $\begin{array}{l}0.139 \\
0.117\end{array}$ \\
\hline & TRAP & $\begin{array}{l}\text { Depression }(+) \\
\text { Sex }(M>F)\end{array}$ & $\begin{array}{l}22.70 \\
5.07\end{array}$ & $\begin{array}{l}1 / 38 \\
1 / 38\end{array}$ & $\begin{array}{l}<0.001 \\
0.030\end{array}$ & $\begin{array}{l}0.374 \\
0.118\end{array}$ \\
\hline \multicolumn{7}{|c|}{ Estimated marginal means (SE) in $z$ values } \\
\hline \multicolumn{2}{|l|}{ Biomarkers } & \multicolumn{2}{|l|}{ Controls } & \multicolumn{2}{|c|}{ Depression } & \\
\hline \multicolumn{2}{|l|}{ Endotoxin ( $z$ value) } & \multicolumn{2}{|l|}{$-0.63(0.14)$} & \multicolumn{2}{|c|}{$+0.74(0.13)$} & \\
\hline \multicolumn{2}{|l|}{ LOOH ( $z$ value) } & \multicolumn{2}{|l|}{$-0.18(0.20)$} & \multicolumn{2}{|c|}{$+0.38(0.19)$} & \\
\hline \multicolumn{2}{|l|}{ NOx ( $z$ value) } & \multicolumn{2}{|l|}{$-0.20(0.50)$} & \multicolumn{2}{|c|}{$+0.50(0.21)$} & \\
\hline \multicolumn{2}{|l|}{ TRAP ( $z$ value) } & \multicolumn{2}{|l|}{$-0.52(0.19)$} & \multicolumn{2}{|c|}{$+0.65(0.18)$} & \\
\hline \multicolumn{2}{|l|}{ AOPP ( $z$ value) } & \multicolumn{2}{|l|}{$-0.12(0.21)$} & \multicolumn{2}{|c|}{$+0.43(0.20)$} & \\
\hline
\end{tabular}

$A O P P$ advanced oxidation protein products, $L O O H$ hydroperoxide; $N O x$ nitric oxide metabolites; - SH groups -sulfhydryl groups; TRAP total radical trapping potential; $P O N 1$ paraoxonase total activity; $M / F$ male/female

and TRAP had significant effects on the three subscales, NOx on HDRSd and TRAP on the HDRSv and HDRSps subscales.

Table 6 shows the results of two multivariate GLM analyses with the four WHOQol-BREF domains as dependent variables, with CAP or root canal LPS as explanatory variables. CAP was significantly associated with lowered ratings on psychological, environment and social domains, while root canal LPS was significantly and inversely associated with the four domains.

Table 3 Results of multivariate GLM analyses with the oxidative and nitrosative stress and antioxidant data as dependent variables

\begin{tabular}{|c|c|c|c|c|c|c|}
\hline Tests & Dependent variables & Explanatory variables & $F$ & $\mathrm{df}$ & $p$ value & Partial eta squared \\
\hline \multirow[t]{4}{*}{ Multivariate \#1 } & \multirow{4}{*}{$\begin{array}{l}\text { AOPP, -SH, LOOH, } \\
\text { PON1, NOx, TRAP }\end{array}$} & Periodontitis & 1.70 & $6 / 33$ & 0.151 & 0.236 \\
\hline & & Smoking & 1.95 & $6 / 33$ & 0.102 & 0.262 \\
\hline & & Sex & 4.94 & $6 / 33$ & 0.001 & 0.473 \\
\hline & & Age & 6.56 & $6 / 33$ & $<0.001$ & 0.544 \\
\hline \multirow[t]{7}{*}{ Multivariate \#2 } & \multirow{4}{*}{$\begin{array}{l}\text { AOPP, -SH, LOOH, } \\
\text { PON1, NOx, TRAP }\end{array}$} & Endotoxin & 4.05 & $6 / 33$ & 0.004 & 0.424 \\
\hline & & Smoking & 1.70 & $6 / 33$ & 0.152 & 0.236 \\
\hline & & Sex & 5.19 & $6 / 33$ & 0.001 & 0.485 \\
\hline & & Age & 7.43 & $6 / 33$ & $<0.001$ & 0.575 \\
\hline & NOx & Endotoxin (+) & 4.16 & $1 / 38$ & 0.048 & 0.099 \\
\hline & TRAP & Endotoxin (+) & 14.73 & $1 / 38$ & $<0.001$ & 0.279 \\
\hline & AOPP & Endotoxin (+) & 4.50 & $1 / 38$ & 0.041 & 0.106 \\
\hline
\end{tabular}

$A O P P$ advanced oxidation protein products, $L O O H$ hydroperoxides, $N O x$ nitric oxide metabolites, $-S H$ groups - sulfhydryl groups, TRAP total radical trapping antioxidant parameter, $P O N 1$ paraoxonase total activity 
Table 4 Results of multivariate GLM analyses with the Hamilton Depression Rating Scale (HRDS). Beck Depression Inventory (BDI), and the WHO Quality of Life (Qol)-BREF scores as dependent variables and root canal endotoxin levels, chronic apical periodontitis (CAP) or biomarkers as explanatory variables

\begin{tabular}{|c|c|c|c|c|c|c|}
\hline Tests & Dependent variables & Explanatory variables & $F$ & df & $p$ value & Partial eta squared \\
\hline \multirow[t]{2}{*}{ Multivariate \#1 } & \multirow[t]{2}{*}{ WHO, BDI, HDRS } & CAP & 5.93 & $3 / 41$ & 0.002 & 0.302 \\
\hline & & Hypertension & 4.34 & $3 / 41$ & 0.010 & 0.241 \\
\hline \multirow[t]{4}{*}{ Between-subject effects } & WHO & $\mathrm{CAP}(-)$ & 10.14 & $1 / 42$ & 0.003 & 0.190 \\
\hline & BDI & $\mathrm{CAP}(+)$ & 10.08 & $1 / 43$ & 0.003 & 0.190 \\
\hline & \multirow[t]{2}{*}{ HDRS } & CAP (+) & 17.03 & $1 / 43$ & $<0.001$ & 0.284 \\
\hline & & Hypertension (+) & 5.03 & $1 / 43$ & 0.030 & 0.105 \\
\hline Multivariate \#2 & WHO, BDI, HDRS & Endotoxin & 25.45 & $3 / 42$ & $<0.001$ & 0.645 \\
\hline \multirow[t]{3}{*}{ Between-subject effects } & WHO & Endotoxin $(-)$ & 15.96 & $1 / 44$ & 0.001 & 0.266 \\
\hline & BDI & Endotoxin (+) & 36.53 & $1 / 44$ & $<0.001$ & 0.454 \\
\hline & HDRS & Endotoxin (+) & 79.27 & $1 / 44$ & $<0.001$ & 0.642 \\
\hline \multirow[t]{2}{*}{ Multivariate \#3 } & \multirow[t]{2}{*}{ WHO, BDI, HDRS } & NOx & 2.84 & $3 / 40$ & 0.050 & 0.176 \\
\hline & & Hypertension & 4.10 & $3 / 40$ & 0.013 & 0.235 \\
\hline \multirow[t]{2}{*}{ Between-subject effects } & BDI & NOx $(+)$ & 7.44 & $1 / 42$ & 0.009 & 0.151 \\
\hline & HDRS & NOx (+) & 5.58 & $1 / 42$ & 0.023 & 0.117 \\
\hline \multicolumn{7}{|c|}{ Estimated marginal means (SE) } \\
\hline \multicolumn{2}{|l|}{ Variables } & \multicolumn{2}{|l|}{$\begin{array}{l}\text { CAP } \\
\text { NO CAP }\end{array}$} & CAP & $\begin{array}{l}\text { Hypertension } \\
\text { NO }\end{array}$ & YES \\
\hline \multicolumn{2}{|l|}{ WHO } & \multicolumn{2}{|l|}{$97.7(4.1)$} & $82.7(2.5)$ & NS & NS \\
\hline \multicolumn{2}{|l|}{ BDI } & \multicolumn{2}{|l|}{$2.3(3.1)$} & $13.5(1.9)$ & NS & NS \\
\hline \multicolumn{2}{|l|}{ HDRS } & $3.6(1.7)$ & & $11.5(1.0)$ & $5.5(1.1)$ & $9.5(1.5)$ \\
\hline
\end{tabular}

HDRS Hamilton Depression Rating Scale, BDI Beck Depression Inventory, WHO WHO Quality of Life-BREF; NOx nitric oxide metabolites

\section{Discussion}

The first major finding of this study is that subjects with CAP and depression show highly increased root canal endotoxin levels as compared to subjects with CAP without depression and normal controls. In addition, there was a very strong positive association between CAP or root canal endotoxin levels and severity of depression as measured using the HDRS

Table 5 Results of multivariate GLM analyses with the three Hamilton Depression Rating Scale (HDRS) subscale scores as dependent variables and chronic apical periodontitis (CAP), root canal endotoxin levels, or oxidative and nitrosative stress biomarkers as explanatory variables

\begin{tabular}{|c|c|c|c|c|c|c|}
\hline Tests & Dependent variables & Explanatory variables & $F$ & $\mathrm{df}$ & $p$ values & Partial eta squared \\
\hline Multivariate \#1 & HDRSd, HDRSv, HDRSps & CAP & 6.23 & $3 / 43$ & 0.001 & 0.303 \\
\hline \multirow[t]{3}{*}{ Between-subject effects } & HDRSd & CAP $(+)$ & 6.42 & $1 / 45$ & 0.015 & 0.125 \\
\hline & HDRSv & $\mathrm{CAP}(+)$ & 18.53 & $1 / 45$ & $<0.001$ & 0.292 \\
\hline & HDRSps & CAP (+) & 9.73 & $1 / 45$ & 0.003 & 0.178 \\
\hline Multivariate \#2 & HDRSd, HDRSv, HDRSps & Endotoxin & 58.58 & $3 / 43$ & $<0.001$ & 0.641 \\
\hline \multirow[t]{3}{*}{ Between-subject effects } & HDRSd & Endotoxin (+) & 21.14 & $1 / 45$ & $<0.001$ & 0.320 \\
\hline & HDRSv & Endotoxin (+) & 62.83 & $1 / 45$ & $<0.001$ & 0.583 \\
\hline & HDRSps & Endotoxin (+) & 32.94 & $1 / 45$ & $<0.001$ & 0.423 \\
\hline \multirow[t]{2}{*}{ Multivariate \#3 } & HDRSd, HDRSv, HDRSps & NOx & 2.97 & $3 / 39$ & 0.043 & 0.186 \\
\hline & & TRAP & 2.96 & $3 / 39$ & 0.044 & 0.185 \\
\hline \multirow[t]{3}{*}{ Between-subject effects } & HDRSd & $\operatorname{NOX}(+)$ & 7.41 & $1 / 41$ & 0.009 & 0.153 \\
\hline & HDRSv & TRAP (+) & 7.48 & $1 / 41$ & 0.009 & 0.154 \\
\hline & HDRSps & TRAP (+) & 6.51 & $1 / 41$ & 0.015 & 0.137 \\
\hline
\end{tabular}

HDRSd HDRS subscore "core depressive symptoms," that is sum of items 1, 2, 3, 7, and 17; HDRSv HDRS subscore "vegetative symptoms," that is sum of items 4, 5, 6, 8, and 16; HDRSps HDRS subscore "physio-somatic symptoms," that is sum of items 11, 12, 13, 14, and 15; NOx nitric oxide metabolites; TRAP total radical trapping antioxidant parameter 
Table 6 Results of multivariate GLM analyses with the four WHO Quality of Life (QoL)-BREF domains (physiological, psychological, social relationships, and environment) as dependent variables and chronic apical periodontitis (CAP) or root canal endotoxin as explanatory variables

\begin{tabular}{|c|c|c|c|c|c|c|}
\hline Tests & Dependent variables & Explanatory variables & $F$ & $\mathrm{df}$ & $p$ value & Partial eta squared \\
\hline Multivariate \#1 & $\begin{array}{l}\text { Physical, psychological, social, } \\
\text { environment }\end{array}$ & CAP & 3.21 & $4 / 41$ & 0.022 & 0.238 \\
\hline \multirow[t]{3}{*}{ Between-subject effects } & Psychological & CAP $(-)$ & 8.12 & $1 / 44$ & 0.007 & 0.156 \\
\hline & Social & CAP (-) & 11.22 & $1 / 44$ & 0.002 & 0.203 \\
\hline & Environment & CAP $(-)$ & 8.61 & $1 / 44$ & 0.005 & 0.164 \\
\hline Multivariate \#2 & $\begin{array}{l}\text { Physical, psychological, social, } \\
\text { environment }\end{array}$ & Endotoxin & 3.84 & $4 / 41$ & 0.010 & 0.273 \\
\hline \multirow[t]{4}{*}{ Between-subject effects } & Physical & Endotoxin $(-)$ & 10.48 & $1 / 44$ & 0.002 & 0.192 \\
\hline & Psychological & Endotoxin $(-)$ & 13.05 & $1 / 44$ & 0.001 & 0.229 \\
\hline & Social & Endotoxin $(-)$ & 9.07 & $1 / 44$ & 0.004 & 0.171 \\
\hline & Environment & Endotoxin(-) & 8.48 & $1 / 44$ & 0.006 & 0.162 \\
\hline \multicolumn{7}{|c|}{ Estimated marginal means (SE) } \\
\hline \multirow[t]{2}{*}{ Variables } & & & \multicolumn{4}{|l|}{ CAP } \\
\hline & & & \multicolumn{2}{|l|}{ NO CAP } & \multicolumn{2}{|l|}{ CAP } \\
\hline \multicolumn{2}{|l|}{ Psychological } & & \multicolumn{2}{|l|}{$26.2(1.4)$} & \multicolumn{2}{|l|}{$21.7(0.8)$} \\
\hline \multicolumn{2}{|l|}{ Environment } & & $12.8(0.6)$ & & $10.5(0.3)$ & \\
\hline \multicolumn{2}{|l|}{ Social } & & \multicolumn{2}{|l|}{$29.3(1.4)$} & \multicolumn{2}{|l|}{$24.6(0.8)$} \\
\hline
\end{tabular}

(psychiatric interview) and BDI (self-rating). The link between periodontitis and depression is important as periodontal disease is a serious public health problem with an estimated prevalence of $47 \%$ [49]. The current findings extend previous reports that dental health and periodontitis may be related to depression. At the population level, a number of studies show a significant association between periodontitis and depression $[27,28]$. Psychiatric patients may have poor oral health status [50], which could aggravate dental care and thus periodontal disease and periodontitis. In addition, patients with clinical depression are more likely to have tooth loss and less likely to use oral health services [51]. However, not all studies support this association, including a study in an elderly population, which found no significant association between depression and measures of oral health, including periodontal disease [52].

Our study shows that the association between depression and CAP is attributable, at least in part, to increased root canal endotoxin levels in periodontitis patients. It is known that the bacteria associated with periodontal disease are predominantly Gram-negative bacteria, including $P$. gingivalis [22, 32]. CAP and chronically increased endotoxin levels in root canals, may play a pathophysiological role in the onset of depression. Preclinical models show that a state of chronic depression may be induced by chronic elevations in endotoxin, using repeatedintermittent endotoxin administration for 4 months [53]. This is further corroborated by previous studies showing that the endotoxin load produced by Gram-negative commensal gut bacteria is increased in depression, especially chronic depression $[15,16$, 20]. The Gram-negative bacteria that play a role in gut-brain axis-linked depression are $H$. alvei, $P$. aeruginosa, M. morganii, P. mirabilis, P. putida, C. koseri, and $K$. pneumoniae [19, 20], while the most important Gramnegative bacteria related to periodontitis are $P$. gingivalis, P. intermedia, F. nucleatum, P. aeruginosa, B. forsythus, C. rectus, and Treponema sp. [22, 32, 33]. A study is underway to determine changes in the microbiome in CAP-related depression (Gomes et al.). Some possibilities are (a) increased endotoxin of $P$. aeruginosa is a common denominator linking depression to "leaky gut" and "leaky teeth"; (b) the endotoxin of $P$. gingivalis is a major determinant of depression, as this bacteria is a major player in CAP [22]; and (c) perhaps most plausible is a general increase in endotoxins through leaky teeth.

CAP is an inflammatory condition whereby accumulation of bacteria in dental plaque biofilms causes lesions in toothsupporting tissues, including gum, connective, and periodontal tissues and eventually alveolar bone [24, 54]. Gram-negative bacteria are keystone periodontal pathogens related to CAP [22]. Accordingly, we found significantly increased root canal endotoxin levels in patients with CAP as compared to healthy controls without periodontitis. The link between CAP and increased root canal endotoxin levels may explain previous findings that inflammation in periodontal disease is mediated by M1 macrophagic pro-inflammatory cytokines $[55,56]$. Increased endotoxin levels activate TLR 2/4 thereby increasing inflammatory responses leading to M1 macrophagic activation [17].

The second major finding of this study is that increased root canal endotoxin levels were strongly associated with enhanced indicants of systemic O\&NS, namely an elevated O\&NS index as well as raised levels of AOPP and NOx. 
This indicates that elevated endotoxins in CAP may lead to systemic responses, including increased NOx production and oxidation of proteins. These findings extent previous data showing that periodontitis is accompanied by systemic inflammatory responses, as exemplified by increased serum levels of CRP [25]. Importantly, we detected that depression was accompanied by increases in the same O\&NS biomarkers. Therefore, increased root canal endotoxin in CAP may be another pathway linking Gram-negative bacteria with systemic O\&NS processes and mood symptoms. Clinical depression is frequently accompanied by activated O\&NS pathways some of which are relevant to the current study, namely increased levels of peroxides [2, 10, 57], lipid peroxidation [2, $10,13,57-60]$, oxidation of proteins $[2,10,60]$, and increased nitrosylation or production of NO [2, 14, 61, 62]. Previously, we have described many mechanisms whereby activated O\&NS pathways may cause neuronal dysfunctions, including increased neurotoxicity and cytotoxicity, neurodegeneration, lowered neurogenesis, neuroplasticity, and neurotrophic expression, collectively referred to as neuroprogression [63]. For example, increased AOPP may induce inflammatory responses, monocytic activation, advanced glycation end products (AGE), and a receptor for AGE (RAGE), while AOPP are potent high-density lipoprotein receptor antagonists [64-66]. Increased NOx may lead to hypernitrosylation, which may induce neurodegenerative responses and neuronal dysfunctions [67].

The third major finding of this study is that root canal endotoxin levels were most strongly associated with the vegetative and physio-somatic components of the HDRS. Previously, we have shown that a raised bacterial load, originating from gut commensal bacteria, is related to chronic fatigue syndrome (CFS), a neuroimmune disorder characterized by physio-somatic symptoms [68]. In CFS, increased LPS load is associated with neurocognitive deficits, abdominal discomfort, muscular tension, and fatigue [69, 70], and with increases in lipid peroxidation, hypernitrosylation [71], and inflammatory responses [70].

In contrast to the a priori hypothesis, we found that TRAP, an index of total antioxidant capacity, was strongly and positively associated with depression, CAP, and increased root canal endotoxin levels. As an index of antioxidant defenses, it was expected that lowered TRAP values would be evident in depression, which is accompanied by activated O\&NS pathways and lowered antioxidant defenses $(10,11)$. Chang et al. [72] reported that depressed patients had significantly lower TRAP levels, which were additionally inversely correlated with the HDRS score and superoxide radical levels. Also, subjects with a history of suicide attempts show decreased TRAP levels [73]. In addition, lowered levels of other antioxidants and antioxidant enzymes are frequently found in depression, including lowered zinc, coenzyme Q10, vitamins E and C, HDL-cholesterol, albumin, tryptophan and tyrosine, glutathione, glutathione peroxidase, and catalase $[2,6,10,60,74]$. Nevertheless, the very strong associations between TRAP, on the one hand, and depression and endotoxin, on the other, may suggest a highly specific response of TRAP to endotoxin in CAP patients. It is possible that elevated endotoxin increases xanthine oxidase activity [75, 76], which in turn increases uric acid [77], an important component of TRAP [78]. Interestingly, at lower concentrations uric acid is an antioxidant, although priming TLR-induced cytokine production, while at higher concentrations uric acid may induce ROS and inflammation [79, 80]. Unfortunately, we did not assay uric acid in this study. Unexpectedly, PON1 total activity is not decreased in depression and is not related to increased endotoxin levels. Indeed, serum PON1 activity is lower in major depression in some [81], but not all [82] studies. A challenge with LPS (intravenously) may reduce PON1 serum activity and induce an inflammatory response [83]. Although we found lowered -SH groups in subtypes of depression, such as prenatal depression (Roomruangwong et al., submitted), the current study was unable to find any changes in -SH groups related to depression, chronic periodontitis, or increased endotoxin.

Importantly, we found that quality of life was significantly lowered in CAP participants and those with elevated root canal endotoxin levels. Such effects may be related to effects of endotoxin inducing O\&NS pathways and inflammation and thus depression or to multiple detrimental effects of O\&NS on the cardiovascular system, including AOPP accelerating arteriosclerosis [11]. Indeed, periodontal disease and periodontitis may predict inflammatory disorders, such as cardiovascular disease and increased mortality in coronary artery disease and diabetes [26, 84, 85]. Furthermore, periodontitis may induce leaky gut [86] thereby aggravating immuneinflammatory and O\&NS responses as well as inducing autoimmune pathways [16], which may further lower quality of life. These findings may be interpreted to indicate that previous reports on relationships between periodontal disease and low self-esteem, feelings of loneliness and elevated psychological stress [29-31] may be attributed to the effects of endotoxin inducing immune-inflammatory and O\&NS pathways and thus depression and stress symptoms. Nevertheless, O'Neil et al. [87] found that the positive association between poor dental health and depression was independent of CRP levels [87]. Future research should examine the associations between CAP, LPS and more adequate inflammatory markers, including serum levels of interleukin-6 and haptoglobin, and intracellular signaling networks, including nuclear factor $\mathrm{kB}$.

This study has some strengths and limitations that should be discussed when interpreting the results. Firstly, this is a case-control study and therefore, no inferences can be made on causality. Secondly, it would have been interesting if we would have assayed uric acid and xanthine oxidase to interpret the effects of endotoxin on TRAP values. It could be argued that some trend-level findings, namely effects of hypertension 
on severity of depression, should be reported as negative. Nevertheless, a mild relationship between hypertension and depression was reported in a recent meta-analysis [88]. In addition, we used background predictors (not only hypertension, but also age and sex) in order to minimize the variance in the data with the aim to delineate more precisely the relationships between the primary dependent (including severity of illness) and independent (including CAP and LPS) variables. Strengths are that we used multivariate analyses to adjust for different background variables and that univariate associations were interpreted only when there were significant multivariate effects, thereby reducing type I errors. The present results require replication, as well as clarification as to interpretation, given that a recent meta-analysis of CAP and depression concluded that, although suggestive, no firm association can made on the basis of data to date [89].

All in all, elevated levels of root canal LPS in CAP are associated with depression and a lowered quality of life, which may be partly explained by activated O\&NS pathways, especially increased NOx and associated hypernitrosylation. Improving dental health, and thereby decreasing CAP, may be especially important in depressed patients, including by attenuating the immune-inflammatory and O\&NS pathways that can underpin depression. This should decrease the twoway interactions of depression and CAP, while enhancing quality of life.

Acknowledgements MM is supported by a CNPq PVE fellowship at the Health Sciences Graduation Program, Universidade Estadual de Londrina. THLB and NRM are supported by CAPES fellowships at the Health Sciences Graduation Program, Universidade Estadual de Londrina. CCG is supported by Institute of Health, School of Dentistry, UFF - Federal Fluminense University, Nova Friburgo, RJ, Brazil. FCM is supported by a FAPESP (Sao Paulo Research Foundation) grant (FAPESP: 2015/03696-1), Sao Paulo, Brazil.

Author Contributions CG, MM, HOV, and SOVN made the design of the study. Participants were recruited and screened by CG. Biomarker assays were performed by FCM, DSB, LSA, HCCP, THLB, and NRM. MM performed the statistical analyses. All authors contributed equally to the writing of the paper. All authors agreed upon the final version of the paper.

\section{Compliance with Ethical Standards}

Conflict of Interest The authors have no conflict of interest with any commercial or other association in connection with the submitted article.

\section{References}

1. Maes M (1995) Evidence for an immune response in major depression: a review and hypothesis. Prog Neuropsychopharmacol Biol Psych 19(1):11-38

2. Maes M, Galecki P, Chang YS, Berk M (2011) A review on the oxidative and nitrosative stress (O\&NS) pathways in major depression and their possible contribution to the (neuro) degenerative processes in that illness. Prog Neuropsychopharmacol Biol Psych 35(3):676-692

3. Maes M (1993) A review on the acute phase response in major depression. Rev Neurosci 4(4):407-416

4. Dowlati Y, Herrmann N, Swardfager W, Liu H, Sham L, Reim EK, Lanctôt KL (2010) A meta-analysis of cytokines in major depression. Biol Psychiatry 67(5):446-457

5. Maes M, Vandoolaeghe E, Neels H, Demedts P, Wauters A, Meltzer HY, Altamura C, Desnyder R (1997) Lower serum zinc in major depression is a sensitive marker of treatment resistance and of the immune/inflammatory response in that illness. Biol Psychiatry 42(5):349-358

6. Maes M, De Vos N, Pioli R, Demedts P, Wauters A, Neels H, Christophe A (2000) Lower serum vitamin E concentrations in major depression: another marker of lowered antioxidant defenses in that illness. J Affect Disord 58(3):241-246

7. Anderson G, Berk M, Dean O, Moylan S, Maes M (2014) Role of immune-inflammatory and oxidative and nitrosative stress pathways in the etiology of depression: therapeutic implications. CNS Drugs 28(1):1-10

8. Che Y, Zhou Z, Shu Y, Zhai C, Zhu Y, Gong S, Wang JF (2015) Chronic unpredictable stress impairs endogenous antioxidant defense in rat brain. Neurosci Lett 584:208-213

9. Mansur RB, Santos CM, Rizzo LB, Cunha GR, Asevedo E, Noto M, Pedrini M, Zeni M (2016) Inter-relation between brain-derived neurotrophic factor and antioxidant enzymes in bipolar disorder. Bipolar Disord 18(5):433-439

10. Liu T, Zhong S, Liao X, Chen J, He T, Lai S, Jia Y (2015) A metaanalysis of oxidative stress markers in depression. PLoS One 10(10):e0138904

11. Maes M, Ruckoanich P, Chang YS, Mahanonda N, Berk M (2011) Multiple aberrations in shared inflammatory and oxidative \& nitrosative stress (IO\&NS) pathways explain the co-association of depression and cardiovascular disorder (CVD), and the increased risk for CVD and due mortality in depressed patients. Prog NeuroPsychopharmacol Biol Psychiatry 35(3):769-783

12. Moylan S, Berk M, Dean OM, Samuni Y, Williams LJ, O’Neil A, Hayley AC, Pasço JA (2014) Oxidative \& nitrosative stress in depression: why so much stress? Neurosci Biobehav Rev 45:46-62

13. Vaváková M, Ďuračková Z, Trebatická J (2015) Markers of oxidative stress and neuroprogression in depression disorder. Oxidative Med Cell Longev 2015:898393

14. Gałecki P, Gałecka E, Maes M, Chamielec M, Orzechowska A, Bobińska K, Lewinski A, Szemraj J (2012) The expression of genes encoding for COX-2, MPO, iNOS, and SPLA2-IIA in patients with recurrent depressive disorder. J Affect Disord 138(3):360-366

15. Maes M, Kubera M, Leunis JC (2008) The gut-brain barrier in major depression: intestinal mucosal dysfunction with an increased translocation of LPS from gram negative enterobacteria (leaky gut) plays a role in the inflammatory pathophysiology of depression. Neuro Endocrinol Lett 29(1):117-124

16. Maes M, Kubera M, Leunis JC, Berk M, Geffard M, Bosmans E (2013) In depression, bacterial translocation may drive inflammatory responses, oxidative and nitrosative stress (O\&NS), and autoimmune responses directed against O\&NS-damaged neoepitopes. Acta Psychiatr Scand 127(5):344-354

17. Lucas K, Maes M (2013) Role of the toll like receptor (TLR) radical cycle in chronic inflammation: possible treatments targeting the TLR4 pathway. Mol Neurobiol 48(1):190-204

18. Lucas K, Morris G, Anderson G, Maes M (2015) The toll-like receptor radical cycle pathway: a new drug target in immunerelated chronic fatigue. CNS Neurol Disord Drug Targets 14(7): 838-854

19. Maes M, Mihaylova I, Kubera M, Leunis JC (2008) An IgMmediated immune response directed against nitro-bovine serum albumin (nitro-BSA) in chronic fatigue syndrome (CFS) and major 
depression: evidence that nitrosative stress is another factor underpinning the comorbidity between major depression and CFS. Neuroendocrinol Lett 29(3):313-319

20. Maes M, Kubera M, Leunis JC, Berk M (2012) Increased IgA and IgM responses against gut commensals in chronic depression: further evidence for increased bacterial translocation or leaky gut. J Affect Disord 141(1):55-62

21. Berk M, Williams LJ, Jacka FN, O’Neil A, Pasco JA, Moylan S, Allen NB, Stuart AL, Hayley AC, Byne ML, Maes M (2013) So depression is an inflammatory disease, but where does the inflammation come from? BMC Med 11(1):1-16.

22. Herath TD, Darveau RP, Seneviratne CJ, Wang CY, Wang Y, Jin L (2016) Heterogeneous Porphyromonas gingivalis LPS modulates immuno-inflammatory response, antioxidant defense and cytoskeletal dynamics in human gingival fibroblasts. Scientific Reports 6:115

23. Nair PNR (2006) On the causes of persistent apical periodontitis: a review. Int Endod J 39(4):249-281

24. Socransky SS (2000) Haffajee AD (2005) Periodontal microbial ecology. Periodontol 38(1):135-187

25. Amar S, Han X (2003) The impact of periodontal infection on systemic diseases. Med Sci Monit 9(12):291-299

26. Kinane DF, Lowe G (2000) How periodontal disease may contribute to cardiovascular disease. Periodontol 23(1):121-126

27. Kumar A, Kardkal A, Debnath S, Lakshminarayan J (2015) Association of periodontal health indicators and major depressive disorder in hospital outpatients. J Indian Soc Periodontol 19(5): 507-511

28. Hsu CC, Hsu YC, Chen HJ, Lin CC, Chang KH, Lee CY, Chong LW, Kao CH (2015) Association of periodontitis and subsequent depression: a nationwide population-based study. Medicine 94(51)

29. Dumitrescu AL, Kawamura M, Dogaru BC, Dogaru CD (2010) Relation of achievement motives, satisfaction with life, happiness and oral health in Romanian university students. Oral Health Prev Dent 8(1):15-22

30. Monteiro da Silva AM, Oakley DA, Newman HN, Nohl FS, Lloyd HM (1996) Psychosocial factors and adult onset rapidly progressive periodontitis. J Clin Periodontol 23(8):789-794

31. Peruzzo DC, Benatti BB, Ambrosano GM, Nogueira-Filho GR, Sallum EA, Casati MZ, Nociti FH Jr (2007) A systematic review of stress and psychological factors as possible risk factors for periodontal disease. J Periodontol 78(8):1491-1504

32. Lovegrove JM (2004) Dental plaque revisited: bacteria associated with periodontal disease. J N Z Soc Periodontol 87:7-21

33. Martinho FC, Leite FR, Chiesa WM, Nascimento GG, Feres M, Gomes BP (2014) Signaling pathways activation by primary endodontic infectious contents and production of inflammatory mediators. J Endod 40(4):484-489

34. Moreno RA, Moreno DH (1998) Escalas de depressão de Montgomery \& Asberg (MADRS) e de Hamilton (HAM-D). Rev Psiquiatr Clin 25:262-272

35. Gorenstein C, Andrade LHSG (1996) Validation of a Portuguese version of the Beck Depression Inventory and the State-Trait Anxiety Inventory in Brazilian subjects. Braz J Med Biol Res 29(4):453-457

36. Fleck M, Louzada S, Xavier M, Chachamovich E, Vieira G, Santos L, Pinzon V (2000) Application of the Portuguese version of the abbreviated instrument of quality life WHOQOL-bref. Rev Saude Publica 34(2):178-183

37. Henrique IFS, Micheli D, Lacerda RB, Lacerda LA, Formigale MLO (2004) Validation release screening test involvement with alcohol, cigarette and other substances (ASSIST). Rev Assoc Med Bras 50(2):199-206

38. Carmo JT, Pueyo AA (2002) Adaptation to Portuguese of the Fagerstrom test for nicotine dependence (FTND) to assess dependence and tolerance to nicotine in smokers. Rev Bras Med 59(1-2):73-80

39. Hanasand M, Omdal R, Norheim KB, Gøransson LG, Brede C, Jonsson $\mathrm{G}$ (2012) Improved detection of advanced oxidation protein products in plasma. Clin Chim Acta 413(9):901-906

40. Gonzalez Flecha BS, Repetto M, Evelson P, Boveris A (1991) Inhibition of microsomal lipid peroxidation by $\alpha$-tocopherol and $\alpha$-tocopherol acetate. Xenobiotica 21(8):1013-1022

41. Panis C, Herrera ACSA, Victorino VJ, Campos FC, Freitas LF, De Rossi T, Colado Simão AN, Cecchini AL (2012) Oxidative stress and hematological profiles of advanced breast cancer patients subjected to paclitaxel or doxorubicin chemotherapy. Breast Cancer Res Treat 133(1):89-97

42. Navarro-Gonzálvez JA, García-Benayas C, Arenas J (1998) Semiautomated measurement of nitrate in biological fluids. Clin Chem 44(3):679-681

43. Hu ML (1994) Measurement of protein thiol groups and glutathione in plasma. Methods Enzymol 233:380-385

44. Richter RJ, Jarvik GP, Furlong CE (2008) Determination of paraoxonase 1 status without the use of toxic organophosphate substrates. Circ Cardiovasc Genet 1(2):147-152

45. Repetto M, Reides C, Carretero MLG, Costa M, Griemberg G, Llesuy S (1996) Oxidative stress in blood of HIV infected patients. Clin Chim Acta 255(2):107-117

46. Martinho FC, Leite FR, Nascimento GG, Cirelli JA, Gomes BP (2014) Clinical investigation of bacterial species and endotoxin in endodontic infection and evaluation of root canal content activity against macrophages by cytokine production. Clin Oral Investig 18(9):2095-2102

47. Martinho FC, Gomes BP (2008) Quantification of endotoxins and cultivable bacteria in root canal infection before and after chemomechanical preparation with $2.5 \%$ sodium hypochlorite. J Endod 34(3):268-272

48. Martinho FC, Chiesa WM, Zaia AA, Ferraz CC, Almeida JF, Souza-Filho FJ, Gomes BP (2011) Comparison of endotoxin levels in previous studies on primary endodontic infections. J Endod 37(2):163-167

49. Eke PI, Dye BA, Wei L, Thornton-Evans GO, Genco RJ (2012) Prevalence of periodontitis in adults in the United States: 2009 and 2010. J Dent Res 91(10):914-920

50. Adeniyi AA, Ola BA, Edeh CE, Ogunbanjo BO, Adewuya AO (2011) Dental status of patients with mental disorders in a Nigerian teaching hospital: a preliminary survey. Spec Care Dent 31(4):134-137

51. Okoro CA, Strine TW, Eke PI, Dhingra SS, Balluz LS (2012) The association between depression and anxiety and use of oral health services and tooth loss. Community Dent Oral Epidemiol 40(2): 134-144

52. Mendes DC, Poswar FO, de Oliveira MV, Haikal DS, da Silveira MF, Martins AM, De Paula AM (2012) Analysis of sociodemographic and systemic health factors and the normative conditions of oral health care in a population of the Brazilian elderly. Gerodontology 29(2):206-210

53. Kubera M, Curzytek K, Duda W, Leskiewicz M, Basta-Kaim A, Budziszewska B, Roman A, Zajicova A (2013) A new animal model of (chronic) depression induced by repeated and intermittent lipopolysaccharide administration for 4 months. Brain Behav Immun 31:96-104

54. Page RC, Schroeder HE (1976) Pathogenesis of inflammatory periodontal disease. A summary of current work. Lab Investig 34(3): 235-249

55. Hasturk H, Kantarci A, Van Dyke TE (2012) Oral inflammatory diseases and systemic inflammation: role of the macrophage. Front Immunol 3:118-138

56. Ara T, Kurata K, Hirai K, Uchihashi T, Uematsu T, Imamura $\mathrm{Y}$, Furusawa K, Kurihara S (2009) Human gingival fibroblasts are 
critical in sustaining inflammation in periodontal disease. $\mathrm{J}$ Periodont Res 44(1):21-27

57. Maes M, Mihaylova I, Kubera M, Uytterhoeven M, Vrydags N, Bosmans E (2010) Increased plasma peroxides and serum oxidized low density lipoprotein antibodies in major depression: markers that further explain the higher incidence of neurodegeneration and coronary artery disease. J Affect Disord 125(1):287-294

58. Maes M, Christophe A, Delanghe J, Altamura C, Neels H, Meltzer HY (1999) Lowered $\omega 3$ polyunsaturated fatty acids in serum phospholipids and cholesteryl esters of depressed patients. Psychiatry Res 85(3):275-291

59. Bilici M, Efe H, Köroğlu MA, Uydu HA, Bekaroğlu M, Değer O (2001) Antioxidative enzyme activities and lipid peroxidation in major depression: alterations by antidepressant treatments. J Affect Disord 64(1):43-51

60. Maes M, Mihaylova I, Kubera M, Leunis JC, Geffard M (2011) IgM-mediated autoimmune responses directed against multiple neoepitopes in depression: new pathways that underpin the inflammatory and neuroprogressive pathophysiology. J Affect Disord 135(1-3):414-418

61. Maes M, Kubera M, Mihaylova I, Geffard M, Galecki P, Leunis JC, Berk M (2013) Increased autoimmune responses against autoepitopes modified by oxidative and nitrosative damage in depression: implications for the pathways to chronic depression and neuroprogression. J Affect Disord 149(1-3):23-29

62. Filipović D, Todorović N, Bernardi RE, Gass P (2017) Oxidative and nitrosative stress pathways in the brain of socially isolated adult male rats demonstrating depressive- and anxiety-like symptoms. Brain Struct Funct 222(1):1-20

63. Leonard B, Maes M (2012) Mechanistic explanations how cellmediated immune activation, inflammation and oxidative and nitrosative stress pathways and their sequels and concomitants play a role in the pathophysiology of unipolar depression. Neurosci Biobehav Rev 36(2):764-785

64. Zheng ZK, Wang J, Hu H, Jiang K, Nie J, Zhang J, Guo H, Qiao X (2013) Short-term inhalation of nitric oxide inhibits activations of toll-like receptor 2 and 4 in the lung after ischemia reperfusion injury in mice. J Huazhong Univ Sci Technol [Med Sci] 33(2): 219-223

65. Witko-Sarsat V, Friedlander M, Khoa TN, Capeillère-Blandin C, Nguyen AT, Canteloup S, Dayer J, Jungers P (1998) Advanced oxidation protein products as novel mediators of inflammation and monocyte activation in chronic renal failure 1, 2. J Immunol 161(5):2524-2532

66. Marsche G, Frank S, Hrzenjak A, Holzer M, Dirnberger, S, Wadsack C, Scharnagl H, Stojakovic T, Heinemann A, Oettik (2009) Plasma-advanced oxidation protein products are potent high-density lipoprotein receptor antagonists in vivo. Circ Res 104(6):750-757

67. Morris G, Berk M, Klein H, Walder K, Galecki P, Maes M (2016) Nitrosative stress, hypernitrosylation, and autoimmune responses to nitrosylated proteins: new pathways in neuroprogressive disorders including depression and chronic fatigue syndrome. Mol Neurobiol $1-21$

68. Maes M (2009) Inflammatory and oxidative and nitrosative stress pathways underpinning chronic fatigue, somatization and psychosomatic symptoms. Curr Opin Psychiatry 22(1):75-83

69. Maes M, Coucke F, Leunis JC (2007) Normalization of the increased translocation of endotoxin from gram negative enterobacteria (leaky gut) is accompanied by a remission of chronic fatigue syndrome. Neuro Endocrinol Lett 28(6):739-744

70. Maes M, Mihaylova I, Leunis JC (2007) Increased serum IgA and IgM against LPS of enterobacteria in chronic fatigue syndrome (CFS): indication for the involvement of gram-negative enterobacteria in the etiology of CFS and for the presence of an increased gut-intestinal permeability. J Affect Disord 99(1-3):237240

71. Maes M, Twisk FN, Kubera M, Ringel K, Leunis JC, Geffard M (2012) Increased IgA responses to the LPS of commensal bacteria is associated with inflammation and activation of cell-mediated immunity in chronic fatigue syndrome. J Affect Disord 136(3): 909-917

72. Chang AH, Sancheti H, Garcia J, Kaplowitz N, Cadenas E, Han D (2014) Respiratory substrates regulate S-nitrosylation of mitochondrial proteins through a thiol-dependent pathway. Chem ResToxicol 27(5):794-804

73. Vargas HO, Nunes SOV, de Castro MP, Bortolasci CC, Barbosa DS, Morimoto HK, Venugopal K, Dodd S (2013) Oxidative stress and lowered total antioxidant status are associated with a history of suicide attempts. J Affect Disord 150(3):923-930

74. Ozcan ME, Gulec M, Ozerol E, Polat R, Akyol O (2004) Antioxidant enzyme activities and oxidative stress in affective disorders. Int Clin Psychopharmacol 19(2):89-95

75. Deitch EA, Taylor M, Grisham M, Ma L, Bridges W, Berg R (1989) Endotoxin induces bacterial translocation and increases xanthine oxidase activity. J Trauma Acute Care Surg 29(12):1679-1683

76. Kahl S, Elsasser TH (2004) Endotoxin challenge increases xanthine oxidase activity in cattle: effect of growth hormone and vitamin $\mathrm{E}$ treatment. Domest Anim Endocrinol 26(4):315-328

77. Tan S, Radi R, Gaudier F, Evans RA, Rivera A, Kirk KA, Parks DA (1993) Physiologic levels of uric acid inhibit xanthine oxidase in human plasma. Pediatr Res 34(3):303-307

78. Rhemrev JP, Van Overveld FWPC, Haenen GRMM, Teerlink T, Bast A, Vermeiden JPW (2000) Quantification of the nonenzymatic fast and slow TRAP in a postaddition assay in human seminal plasma and the antioxidant contributions of various seminal compounds. J Androl 21(6):913-920

79. Sautin YY, Johnson RJ (2008) Uric acid: the oxidant-antioxidant paradox. Nucleosides, Nucleotides Nucleic Acids 27(6-7):608-619

80. Crişan TO, Cleophas MC, Oosting M, Lemmers H, ToenhakeDijkstra H, Netea MG, Jansen TL, Joosten LA (2016) Soluble uric acid primes TLR-induced proinflammatory cytokine production by human primary cells via inhibition of IL-1Ra. Ann Rheum Dis 75(4):755-762

81. Bortolasci CC, Vargas HO, Souza-Nogueira A, Barbosa DS, Moreira EG, Nunes SOV, Berk M, Dodd S (2014) Lowered plasma paraoxonase (PON) 1 activity is a trait marker of major depression and PON1 Q192R gene polymorphism-smoking interactions differentially predict the odds of major depression and bipolar disorder. J Affect Disord 159:23-30

82. Kodydková J, Vávrová L, Zeman M, Jirák R, Macášek J, Staňková B, Turzicka E, Zak A (2009) Antioxidative enzymes and increased oxidative stress in depressive women. Clin Biochem 42:1368-1374

83. Terres de Campos F, Rincón JAA, Acosta DAV, Silveira PAS, Pradieé J, Corrêa MN, Gasperin BG, Pfeifer LFM (2017) The acute effect of intravenous lipopolysaccharide injection on serum and intrafollicular HDL components and gene expression in granulosa cells of the bovine dominant follicle. Theriogenology 89:244-249

84. Saremi A, Nelson RG, Tulloch-Reid M, Hanson RL, Sievers ML, Taylor GW, Shlossman M, Bennett PH (2005) Periodontal disease and mortality in type 2 diabetes. Diabetes Care 28(1):27-32

85. Humphrey LL, Fu R, Buckley DI, Freeman M, Helfand M (2008) Periodontal disease and coronary heart disease incidence: a systematic review and meta-analysis. J Gen Intern Med 23(12):2079-2086

86. Hajishengallis G (2015) Periodontitis: from microbial immune subversion to systemic inflammation. Nature Rev Immunol 15(1):30 44

87. O’Neil A, Berk M, Venugopal K, Kim SW, Williams LJ, Jacka FN (2014) The association between poor dental health and depression: findings from a large-scale, population-based study (the NHANES study). Gen Hosp Psychiatry 36(3):266-270 
88. Li Z, Li Y, Chen L, Chen P, Hu Y (2015) Prevalence of depression in patients with hypertension: a systematic review and meta-analysis. Medicine (Baltimore) 94(31):e1317
89. Araújo MM, Martins CC, Costa LC, Cota LO, Faria RL, Cunha FA, Costa FO (2016) Association between depression and periodontitis: a systematic review and meta-analysis. J Clin Periodontol 43(3):216-228 